\title{
Fertility Postponement and Regional Patterns of Dispersion in Age at First Birth: Descriptive Findings and Interpretations*
}

\section{Mathías Nathan, Ignacio Pardo}

\begin{abstract}
Previous studies have documented an increasing heterogeneity in firstbirth timing in countries experiencing the postponement transition. Sobotka (2004), for instance, showed a rising dispersion in age at first birth in developed countries, particularly in the United Kingdom and the United States, where the timing polarisation between more and less advantaged women is most evident. However, these studies have included few countries outside Europe and North America, and lack a thorough interpretation of the rising dispersion in first births.

Our aim is to compare the evolution of dispersion in age at first birth in countries in Europe, East Asia, North America and South America.

Using data from the Human Fertility Database and the Human Fertility Collection, we describe the evolution of the period mean age at first birth and its variance for 21 countries since 1970 .

In line with previous studies, our results show a widespread pattern of increasing heterogeneity in age at first birth after the onset of the postponement transition, although with marked differences among regions and countries. The greatest heterogeneity can be found in countries where timing of family formation varies greatly among women with different socioeconomic status. Chile and Uruguay, in particular, exhibit the highest heterogeneity even though they are at the beginning of the postponement transition. There is no general explanation of why dispersion increased as the mean age at first birth rose. Further studies in this area should investigate causes and interpretations of this trend, and develop measures for studying heterogeneity in fertility timing.
\end{abstract}

Keywords: Fertility · Fertility postponement - Dispersion in age at first birth - Agespecific fertility rates

This article contains supplementary material in the form of a Data Appendix:

DOI 10.12765/CPoS-2019-08en

URL: http://www.comparativepopulationstudies.de/index.php/CPoS/article/view/290/278. 


\section{Introduction}

The postponement of childbearing has been the central focus of tempo studies in fertility research over the last two decades (Balbo et al. 2013). While a large body of research has focused on its driving forces and consequences (Beets 2010; Billari et al. 2006; Kohler et al. 2002; Mills et al. 2011; Ní Bhrolcháin/Beaujouan 2012; Sobotka $2004,2010)$, the evolution of heterogeneity in age at first birth across countries and regions has rarely been studied.

Heterogeneity in age at first birth is not only crucial for understanding the evolution of fertility changes but also relevant in itself. Dispersion levels show the diffusion of an emerging reproductive norm. For instance, an increasing concentration of first birth in a late age interval evidences widespread late-childbearing behaviours. Conversely, a more dispersed schedule of age at first birth shows the coexistence of different types of reproductive behaviours and a merely partial diffusion of the new fertility norm. Moreover, even greater heterogeneity in age at first birth possibly suggests high levels of social inequality and stratified life courses among socioeconomic groups (Sobotka 2004).

The few studies that analysed the dispersion in the age at first birth in the context of fertility postponement, describing its evolution in specific countries or regions, focused almost exclusively on Europe and the United States (Burkimsher 2015; Kohler et al. 2002; Philipov 2017; Sobotka 2004). In those regions, whereas Kohler et al. (2002) had predicted an increasing concentration of childbearing at older ages as a result of the advancement of fertility postponement, other researchers showed that this shift was in fact followed by increasing socioeconomic differences in fertility timing (Beets 2010; McLanahan 2004; Ravanera/Rajulton 2006; Rendall et al. 2010; Sobotka 2004, 2010).

Philipov (2017) found that the transition towards a late fertility regime in Europe was being coupled with growing heterogeneity in the timing of first births and interpreted this as macro-evidence of the diversification of life courses, in which first births occur over a longer reproductive life span. Most studies, however, tend to highlight inequality, such as growing educational disparities among women, as the key factor behind reproductive polarisation, especially in highly unequal countries (United States, United Kingdom, Latin American countries). In any case, no comprehensive explanation has indisputably coupled the evolution of dispersion in age at first birth with increasing differences in reproductive careers across different socioeconomic groups. It is reasonable to assume that both processes might foster dispersion concurrently, although one of them may have more impact, depending on the regional and national context.

Our contribution lies in describing different patterns in the evolution of dispersion in age at first birth and in discussing interpretations. More precisely, we describe dispersion in countries going through the postponement transition in eight regions of the world, broadening the scope of the inquiry from previous studies in terms of number of countries and years examined. We aim to compare the evolution of dispersion in European and non-European countries as they move towards a late-fertility regime, identify regional trends and patterns, and discuss theoreti- 
cal and methodological implications. We believe that revealing different dispersion patterns may contribute to a more thorough description of the unfolding of fertility postponement in several contexts.

\section{Postponement transition and heterogeneity in the age schedule of first birth}

The term "postponement transition" (PT) was introduced by Kohler et al. (2002) to describe the widespread and pervasive increase in the period mean age at first birth (MAB1) in developed countries since 1970. The period mean age at first birth (MAB1) increased between 3 and 5 years in European countries from 1970 to 2005, during a steady decrease of fertility levels (Billari et al. 2006; Sobotka 2010). Researchers have identified a broad set of causes behind this shift towards late childbearing. These include the spread of the contraceptive pill, the increase in women's educational attainment and participation in the labour market (Beets 2010; Billari et al. 2006; Frejka/Sardon 2006; Kolher et al. 2002; Mills et al. 2011; Sobotka 2004, 2010, 2017).

According to the literature, the onset of the PT varies across countries and regions. The PT started in the early 1970s in Northern Europe and most Western European countries, while in Southern European countries the onset took place in the early 1980s, and during the 1990s in Central and Eastern European countries, following the collapse of socialist regimes (Beets 2010; Billari/Liefbroer 2010; Kohler et al. 2002; Philipov 2017; Sobotka 2004). Outside Europe, Canada and the United States began experiencing postponement transition in the 1970s (Beets 2010; Sobotka 2004). In East Asian countries, women born in the 1950s and 1960s showed the first signs of a change towards a later entry into motherhood, making the phenomenon noticeable from a period perspective in the 1970s and 1980s (Frejka et al. 2010). Finally, a set of Latin American countries have shown signs of an initial shift towards fertility postponement since 2000, according to Rosero-Bixby et al. (2009) and Esteve et al. (2012). Argentina, Chile, and particularly Uruguay - all countries in South America's Southern Cone - seem to be at the forefront of this change (Lima et al. 2018; Pardo/Cabella 2018; also see Appendix, Table 2).

It is useful to note different starting points and paces in the MAB1, since its dispersion is usually low before PT, but is expected to increase as the process unfolds. Previous studies show the MAB1 before the onset of fertility postponement within the 23.5-24.5 years interval for almost every country in Northern, Western, and Southern Europe. In the latter case, the average MAB1 was slightly higher than in the other regions mentioned. Former socialist countries, on the other hand, exhibited a lower MAB1 at the start of the PT in comparison to the rest of Europe (less than 23 years) (Beets 2010; Sobotka 2004). After the onset, the pace of postponement also exhibited marked differences among regions. For example, Southern European countries experienced a rapid increase of MAB1 and this region now displays the highest MAB1 in the world (Philipov 2017). Presently, MAB1 continues to rise in most developed countries, although the pace of increase is slowing down (Philipov 
2017), fostering debate on whether the PT will reach an end soon (Goldstein et al. 2009; Sobotka 2004).

Research carried out in developed countries showed increasing differences in the age at first birth between social groups, particularly in the United Kingdom and the United States (McLanahan 2004; Ravanera/Rajulton 2006; Rendall et al. 2010; Sobotka 2010). Philipov (2017) also showed that heterogeneity increased in European countries some years after the onset of fertility postponement and remained at a high level towards the end of the PT. Using the standard deviation of the mean age at first birth (sdMAB1) he identified different stages. First, a period when sdMAB1 did not increase, followed by a longer trend where sdMAB1 did increase continuously and a final stage where sdMAB1 stabilised at high levels. Increasing dispersion around the mean age may be seen as a combination of period effects affecting young people, processes of "learning of new behaviour" influencing new cohorts and changes in ideas driving diffusion (Philipov 2017).

Comparative studies showed that cross-country and regional differences in the PT are related to a diverse array of determinants, such as institutional and cultural settings, educational composition of the population, or prevailing social norms, among others (Sobotka 2010; Billari 2004; Gustafsson et al. 2002). In particular, the emergence of different fertility patterns in the context of the PT can be construed as the result of a) the specific influence of each determinant of postponement at the country level, and b) the different starting points at the onset of the process (Frejka/ Sardon 2006). Higher educational attainment (via opportunity costs or time constraints due to enrolment), partnership instability and uncertain conditions within the labour market are often-cited factors that foster delayed motherhood at the micro level (Ni Bhrolcháin/Beaujouan 2012; Rindfuss/Brauner-Otto 2008; Gustafsson/ Kalwij 2006). Intergenerational transmission of timing preferences and prevailing social norms are also mentioned as well-established determinants (De Valk/Liefbroer 2007; Liefbroer/Billari 2010).

Within the field of fertility research, transition theories have relied on both structural changes and diffusion processes to explain the spread of a new reproductive pattern among the population (Bongaarts/Watkins 1996; Kohler et al. 2002; Lesthaeghe 2010). From this approach, postponement of childbearing is expected to be initially adopted by women with high socioeconomic status, in response to changing external (social, economic) conditions and incentives. After this initial phase, a "bandwagon effect" comes into play, with social interactions encouraging other members of the population to adopt the new behaviour (Goldstein et al. 2009). In this perspective, more disadvantaged women are not entirely "immune" to the overall change in reproductive values, attitudes and behaviour; rather, they should follow the same trend with certain time lag. But to what extent do socioeconomic inequalities limit the spread of long-term changes in fertility among less advantaged groups?

Evidence has shown growing socioeconomic heterogeneity of fertility patterns in countries with "liberal" welfare regimes, and a more homogeneous impact in those countries with universal provision of childcare services (Rendall et al. 2010; Sullivan 2005). Countries with family-oriented welfare regimes and low institutional 
compatibility between childrearing and employment (e.g. countries in Southern Europe) also experience increasing heterogeneity (Rendall et al. 2010).

From a life-course perspective, delaying motherhood is one dimension of the general trend towards delayed transitions to adulthood (Billari/Liefbroer 2010; Furstenberg et al. 2005; Billari/Wilson 2001). Changes in the life course trajectories of young adults in this typically "demographically dense" period (Rindfuss 1991) result in more diverse transitions to adulthood. This process in which the social and temporal organisation of the life course become less guided by normative, legal or organisational rules (Billari/Wilson 2001; Elzinga/Lifbroer 2007) provides, as a result, a much less clear normative order of events making it more common for people to experience multiple events (e.g. marriages) or combine multiple roles (e.g. worker and student).

The age schedule of events of transition to adulthood is as important as its sequence with other events of transition to adulthood (e.g. leaving parental home, finishing school) with both dimensions influencing one another. Evidence in a variety of countries has shown that women of different social status undergo different sequences in transition to adulthood. Women of lower status not only have a shorter transition to adulthood but also a sequence in which some events are omitted, thus motherhood does not necessarily follow post-secondary graduation, work and marriage/union (Ravanera/Rajulton 2006).

This tendency could favour the bifurcation of the life course (Schulze/Tyre// 2002), given that in the middle and upper social strata the normative sequence is more frequent and, in that context, the postponement of the entire process "naturally" increases the age to the first child. The differential appropriation of delaying type of behaviour by women of these strata suggests that the influence of ideas is not the only explanation, but that there are costs and restrictions that foster heterogeneity by strata (Nee/s/Perelli-Harris 2013). In addition, educational expansion could be contributing to said increasing heterogeneity to the extent that in such a context, those left behind progressively move away from the average age to the first child. ${ }^{1}$ In fact, a growing body of evidence links increasing heterogeneity to differences in work experience duration and the number of years spent in education (Nicoletti) Tanturri 2008). In any case, micro-level variables such as educational attainment interact with country-level variables such as institutional arrangements and policy regimes (Billari 2004).

Considering the future evolution of dispersion in age at first birth, a possible convergence in fertility by education might generate expectations about diminishing heterogeneity within countries. However, it is reasonable to believe this trend would be limited to certain regions, at least in the short term. Recently, Basten et al. (2014) gathered experts who concluded that diminishing education-fertility differentials are expected especially in Latin America, Middle East and Southern Europe, but are unlikely in other areas, such as the United Sates.

1 This process can also be described by focusing on the educational composition of the population from a cohort perspective (Rendall et al. 2010). 


\section{Data and measures}

Using data from the Human Fertility Database (HFD) and the Human Fertility Collection (HFC), ${ }^{2}$ we jointly examined the evolution of the period MAB1 and sdMAB1 from 1970 to $2014 .{ }^{3}$ We also analysed the share of first birth rates before age 20 and after age 29 and the shape of age-specific fertility schedules (ASFR1) in selected years. To discuss the accuracy of the standard deviation as an indicator of heterogeneity in the age at first birth, we also compared the sdMAB1 with the coefficient of variation (CV1). The HFD provides reliable fertility data and estimates that can be compared across countries. The HFC, on the other hand, was originally designed as a supplementary dataset to broaden the scope of countries that are covered by the HFD. Due to variability in data origins and estimation methods, the HFC data do not meet all the quality standards of the HFD and therefore estimates should be analysed with caution. In this work, we used the HFC for a certain number of countries, not available in the HFD, that we considered relevant to improve our depiction of the specific fertility patterns by region.

We selected 21 countries in eight regions: Northern Europe, Western Europe, Southern Europe, Central \& Eastern Europe, post-Soviet countries, North America, East Asia, and South America. Compared to recent studies, our research brings a larger number of countries and regions under analysis, thereby expanding our understanding of the unfolding postponement transition. We selected no more than three countries per region, giving priority to those countries with quality data and well covered in the fertility literature. With a few exceptions, all chosen countries have available data sets beginning in 1970 and continuing until at least 2010 (see Appendix, Table A1). Given that countries started the postponement transition at different points in time, we plotted the joint evolution of the MAB1 and the sdMAB1 without a calendar marker.

The model of the PT has been described from a period perspective. Changes in the MAB1 and sdMAB1, however, are the outcome of cohort-driven fertility changes as well as contextual factors associated with period effects. The mean age at first birth is usually measured from a period approach; however, the examination of heterogeneity in the timing of first births has relied equally on period and cohort approaches. We used a period perspective to examine the evolution of MAB1 and sdMAB1, as we intend to compare aggregate measures for particular years, tracing the course of the PT.

A theoretical sketch of this joint evolution can be useful to understand how the mean age and the standard deviation are expected to evolve in each country. We plot the MAB1 in the horizontal axis and its standard deviation on the vertical axis,

2 The HFD and the HFC are provided by Max Planck Institute for Demographic Research (Germany) and Vienna Institute of Demography (Austria). Available at www.humanfertility.org and www.fertilitydata.org (data downloaded on October 2016).

3

Both variables were available for most countries, when this was not the case they were computed with data from HFC. 
Fig. 1: Theoretical paths of the joint evolution of the mean age at first birth and its standard deviation sdMAB1

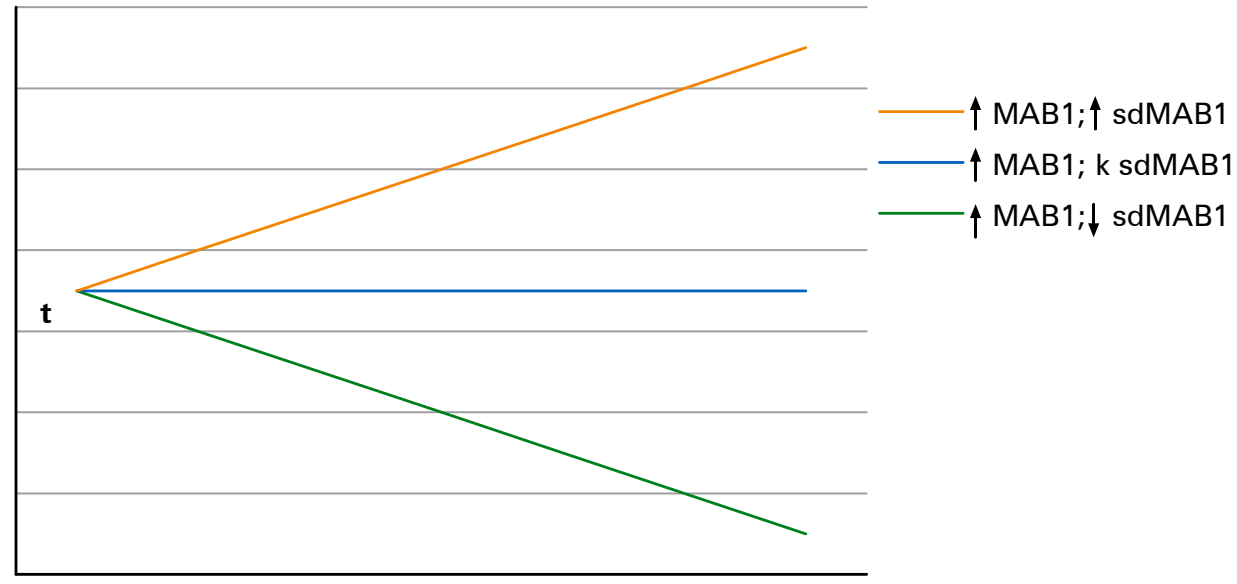

MAB1

$\uparrow \mathrm{MAB} 1 ; \mathrm{k}$ sdMAB1

ASFR1

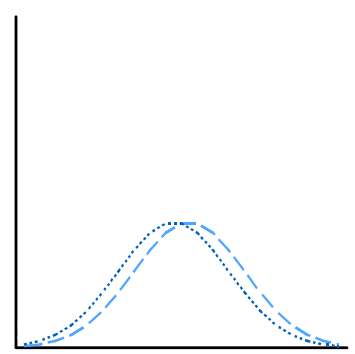

Age

$\mathrm{t}$ $\uparrow \mathrm{MAB} 1 ;$ 个sdMAB1

ASFR1

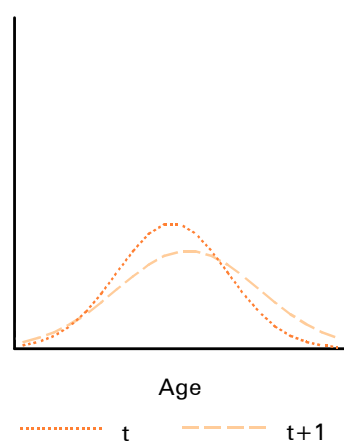

$\uparrow \mathrm{MAB} 1 ; \downarrow \mathrm{sdMAB} 1$

ASFR1

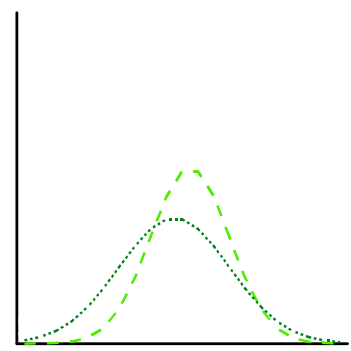

Age $t+1$

$k=$ constant over time

Source: own design

and assume that $t$ represents the first data point, i.e. the year at the onset of the postponement transition (Fig. 1). Assuming a linear relation between these two variables, one stylised path shows an increasing mean age while the standard deviation remains constant (blue line). Another two paths might be observed, while the mean age increases: i) a linear increase (yellow line) or ii) a linear decrease of the standard deviation (green line). Stylised age schedules associated with these paths can also be modelled for two moments in time, assuming a normal distribution of the ASFR1. 
The peak of the curve moves to the right due to an increase in the mean age at first birth and the shape of the curve varies according to dispersion levels.

\section{$4 \quad$ Results}

\subsection{Joint evolution of the mean age at first birth and its standard deviation}

Our results confirm the increasing dispersion of first-birth rates by age as a notable trend throughout the postponement transition. In light of this evidence, the scope of the statement is broadened, since we now know this did not happen exclusively in European countries, as stressed by Philipov (2017), or in other developed (Sobotka 2004) and non-developed countries (Lima et al. 2018; Pardo/Cabella 2018; Nathan et al. 2016) but rather more extensively, as shown in Figure 2.

Overall, marked differences exist among countries and regions regarding level and pace of changes in the MAB1 and sdMAB1. As also stated by Philipov (2017), countries in Northern Europe show a very similar pattern of steady increase in both the MAB1 and sdMAB1 (at least after the first years of increase in the MAB1), while post-Soviet countries exhibit a much more modest increase in the MAB1 and do not reach high levels of dispersion. Eastern Asia countries (Japan and Taiwan) experienced an important increase of the sdMAB1, having begun at very low levels. On the other hand, the dispersion of first birth rates increased in England and Wales and the United States, along with a slow pace of postponement.

However, the MAB1 and sdMAB1 did not start to increase at the same time in all cases. In Northern, Eastern, and Southern Europe, East Asia, and Canada, the start of the increase in the sdMAB1 lagged behind that of the MAB1. Our results show this happened once the MAB1 reached 26 years of age. Those countries fit the model described by Philipov (2017), whereby the PT is expected to evolve in 3 phases, as mentioned above: 1) constant dispersion over time, during the first years after the MAB1 starts to increase, 2) increasing dispersion later on, and 3) a stabilisation of levels of dispersion at higher levels towards the end of the process. However, our evidence shows that this does not hold for countries where the PT started later (as in Eastern European, post-Soviet and South American countries). In those countries, the MAB1 and its dispersion increased jointly, since the beginning of the transition. They also showed lower base levels of the MAB1 (below 24 years) compared to countries where the PT began earlier. The evolution of the MAB1 and sdMAB1 in the United States also follows the latter pattern, despite having experienced the onset of the PT at the beginning of the 1970s.

Some of the most relevant conclusions arising from these results are those linked to the stabilisation of sdMAB1 at high levels. First, the sdMAB1 in early-postponing countries seems to have stabilised at approximately 5-6 years during the later stages of postponement. Among developed countries, England and Wales, and the United States exhibit the highest heterogeneity in age at first birth, followed by Southern European countries. Also, Central and Eastern European countries also 
Fig. 2: $\quad$ Evolution of the mean age at first birth (MAB1) and its standard deviation ( $(\mathrm{dMAB} 1$ ) in selected countries by region
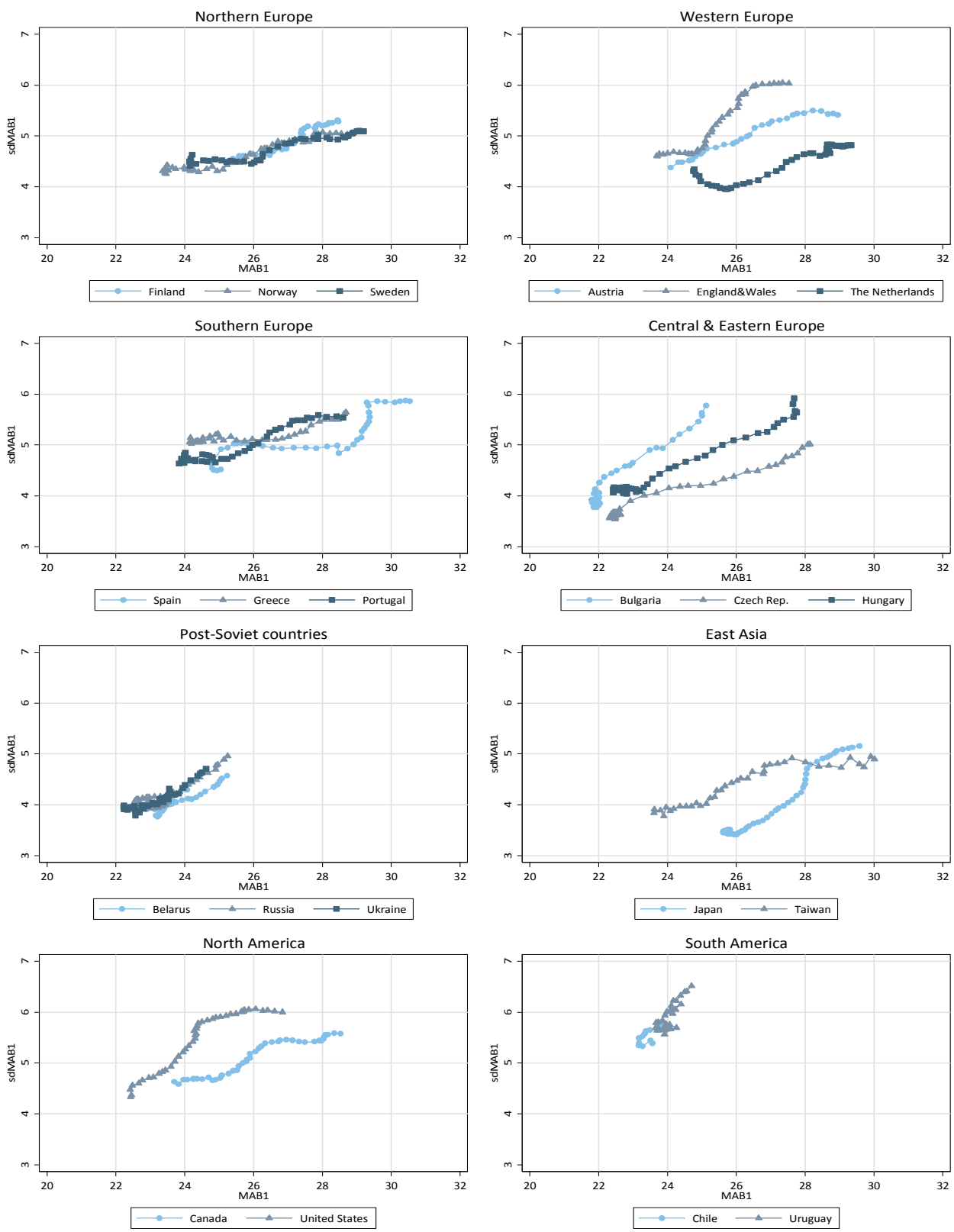

Source: own calculations based on data from Human Fertility Database and Human Fertility Collection 
reached high levels of dispersion in their rapid transition to a late-fertility regime. Remarkably, Uruguay started the postponement transition at the end of the 1990s and has reached the highest level of dispersion to date.

Moreover, some countries follow unique paths that depart from the general trend. In the Netherlands the sdMAB1 decreased over the first years of the PT until MAB1 reached age 26, after which sdMAB1 increased. In Spain, sdMAB1 was quite high at the onset but remained almost unchanged while the mean age at first birth experienced a sharp increase, from 24 to 29 years. Thereafter, standard deviation increased only after 15 years of fertility postponement. ${ }^{4}$

As this broader picture shows a certain degree of heterogeneity among countries and regions, it calls for a better understanding of the demographic processes that may lie behind an increase in the sdMAB1, as different patterns of change in fertility timing may produce a similar result in terms of dispersion. Descriptions tend to focus on the decline in adolescent fertility and the simultaneous increase in fertility rates at age 30 and above, assuming that when those two trends do not evolve at the same pace, it is reasonable to expect increasing heterogeneity in period measures. Our results show the proportion of first births after age 29 has increased in every country almost without any exception since the onset of their respective PT (Fig. 3).

Greater differences were found between regions and countries when analysing the evolution of the share of first births occurring before age 20. In some regions, the weight of teenage fertility started to decrease almost in parallel with the rise in childbearing at older ages (Northern and Southern Europe). In other regions or countries, such as England and Wales or Uruguay, the percentage of first births at younger ages remained stable or decreased only slightly and remains quite high, fuelling an increase in dispersion.

Finally, in other countries (Japan, the Netherlands) there was little change in the share of first births before age 20, but these countries already possessed low levels of teenage fertility at the onset of the PT. In any case, dispersion is determined not only by changes in both extremes of the age schedule range but also by changes in first birth rates at ages 20 to 29. Therefore, a broader picture appears when analysing the evolution of all age-specific fertility rates for first births.

\subsection{Age-specific fertility patterns}

Figure 4 depicts four different patterns of age schedule for first birth rates (ASFR1). Firstly, some countries (for example, Sweden and the Netherlands) exhibit low dispersion levels, both at the onset and at advanced phases of fertility postponement (Group A). Secondly, there are countries with very low dispersion at the onset of the PT that later experienced large increases in the sdMAB1, for instance, ex-socialist countries in Eastern Europe and, to a lesser extent, East Asia (Group B). A third

4 This might be the reason why Kohler et al. (2002) proposed the "rectangularization" hypothesis, missing the rapid increase in dispersion that took place after 2002 in countries like Spain. 
Fig. 3: $\quad$ Share of first birth rates (FBR) before age 20 and after age 29 in selected countries by region
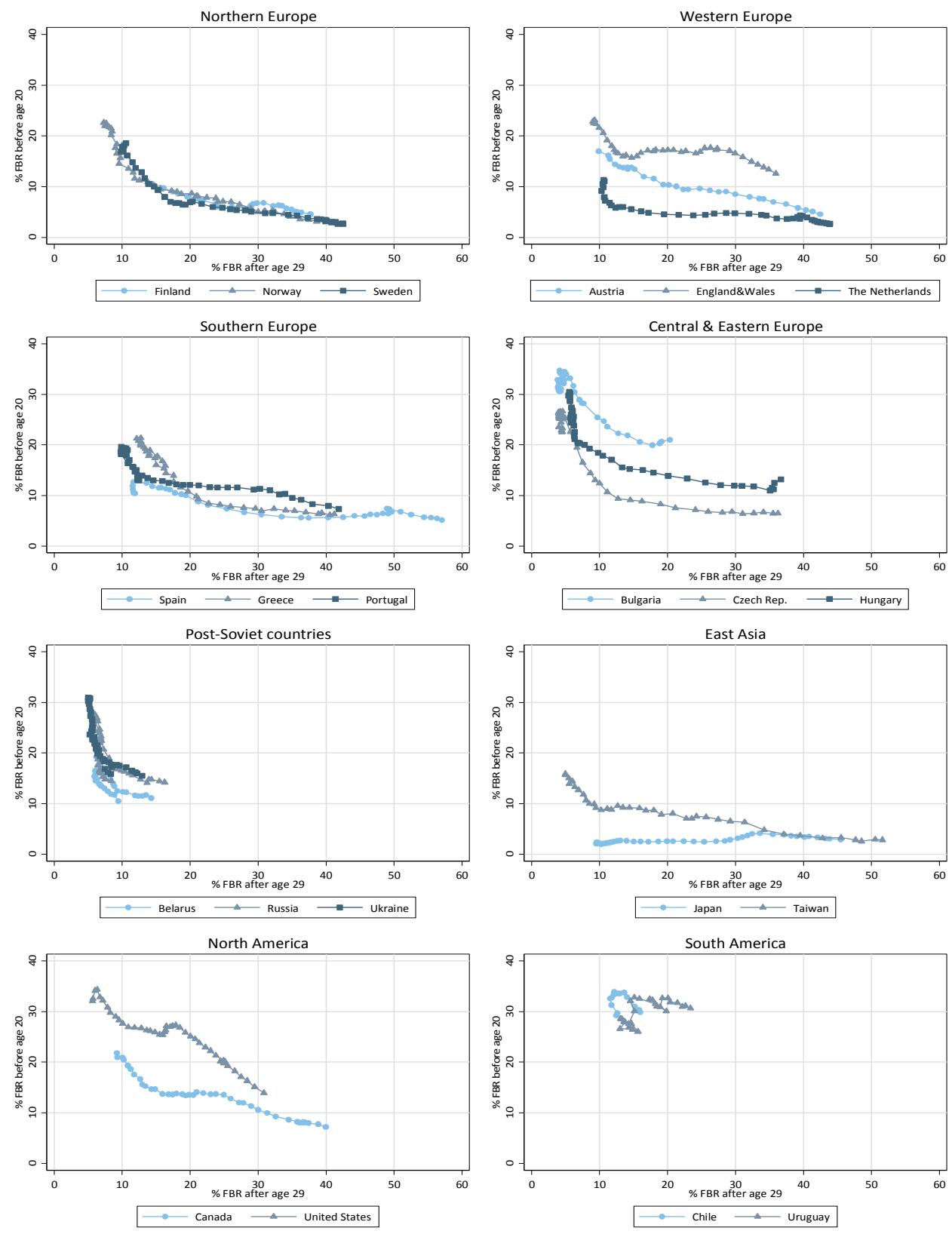

Source: own calculations based on data from Human Fertility Database and Human Fertility Collection 
group of countries shows high dispersion levels at the onset and a small increase in the sdMAB1 (countries in Southern Europe; Group C). Finally, the fourth group of countries reached the highest dispersion levels without having reached an advanced stage of the postponement transition (namely, England and Wales, the United States, and South American countries) (Group D). In these countries, the relative distribution of the ASFR1 does not show a normally distributed curve. Instead, it appears to reflect a polarised pattern, consistent with some of the recent literature on these three countries (Chandola et al. 2002; Lima et al. 2018; Nathan et al. 2016; Sullivan 2005). Polarisation implies widening gaps between subgroups of population, usually with different socioeconomic status, and it tends to take place when less advantaged women show no significant signs of birth postponement, while women who are better positioned in the social structure exhibit a pronounced shift in the timing of entering into motherhood (Sobotka 2004).

Fig. 4: $\quad$ Share of ASFR1 in selected countries, period 1980-2010

Group A
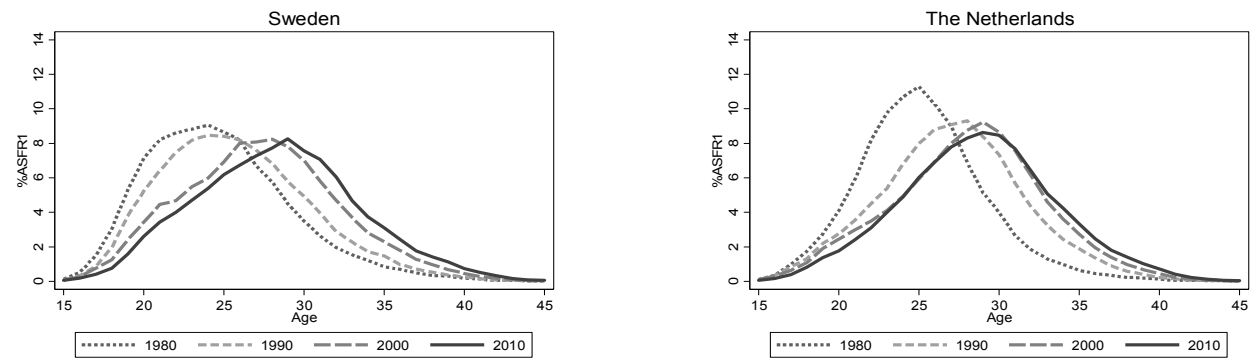

Group B
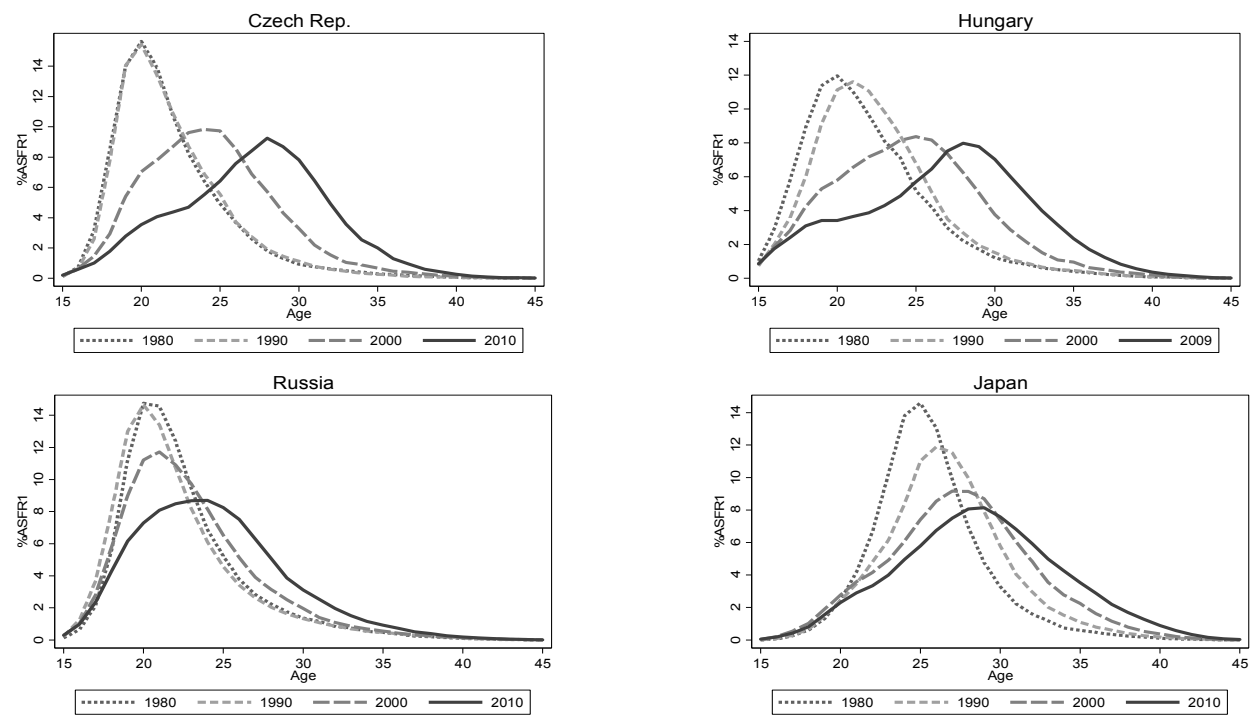
Fig. 4: Continuation

Group C
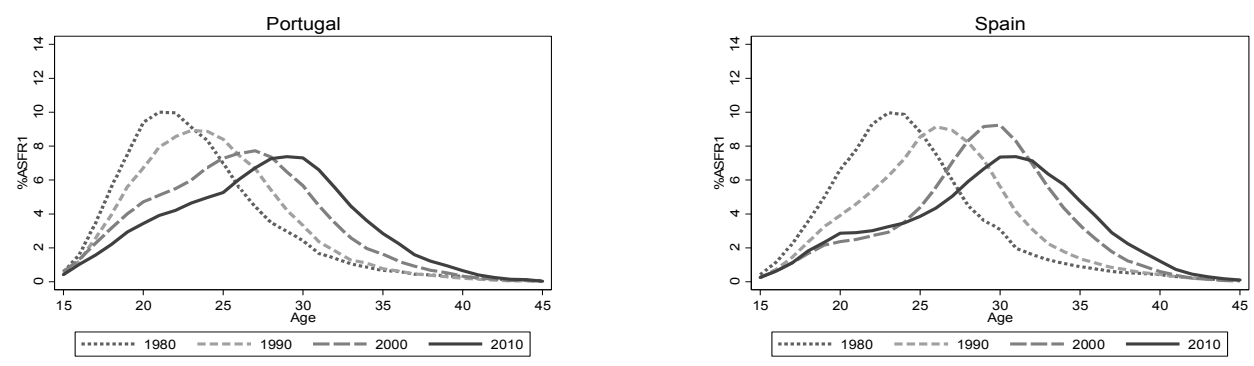

Group D
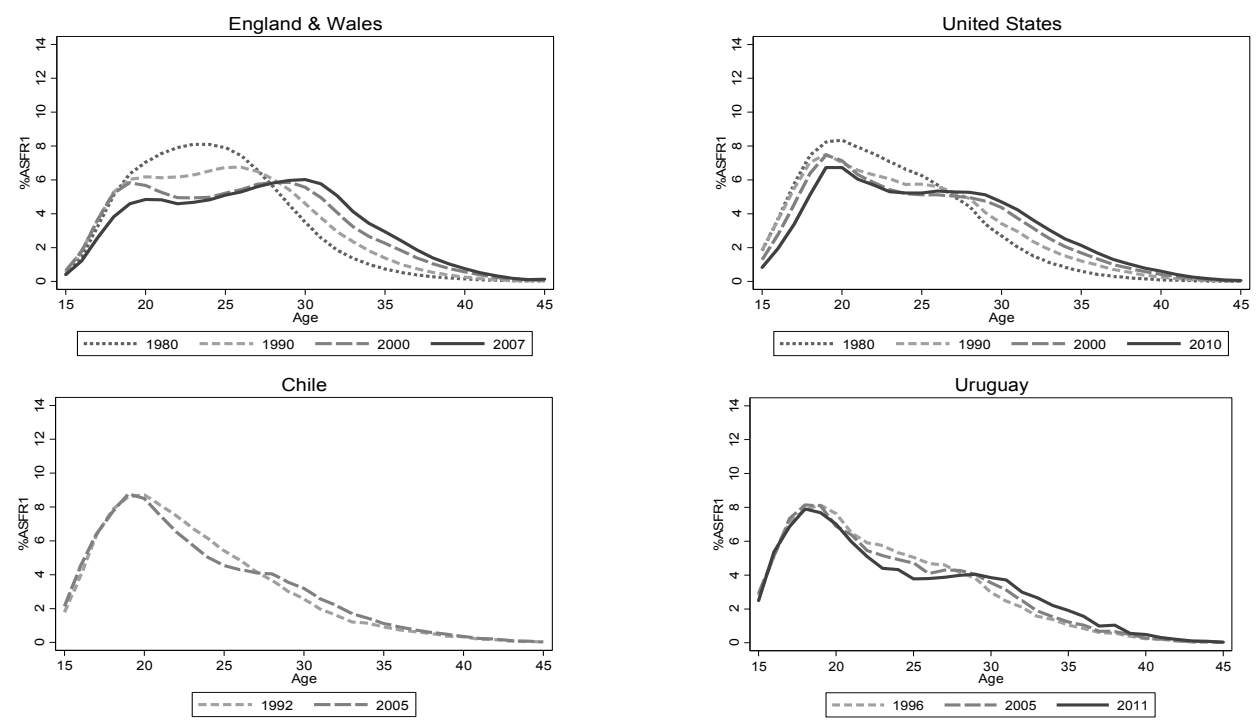

Source: own calculations based on data from Human Fertility Database and Human Fertility Collection

The emergence of this pattern in South American countries may be made more visible by comparing the pattern of the ASFR 1 with other countries at similar stages of the PT - i.e. those with the same MAB1 (see Fig. 5). When countries are compared at the point at which the MAB1 equals 23.7 years, Uruguay and Chile show a slightly more polarised pattern than other countries, whereas by the end of the Uruguayan time span (2011), when the MAB1 equals 24.7, this pattern becomes much more pronounced. At this point, Uruguay resembles the United States - where the MAB1 reached 24.7 in 1996 - while differing from the rest of the countries. A similar pattern is observed in Chile at its highest MAB1 (not shown). 
Fig. 5: $\quad$ Share of ASFR1, sdMAB1, and modal age at first birth for selected countries for the year in which $\mathrm{MAB} 1=23.7$ and $\mathrm{MAB} 1=24.7$
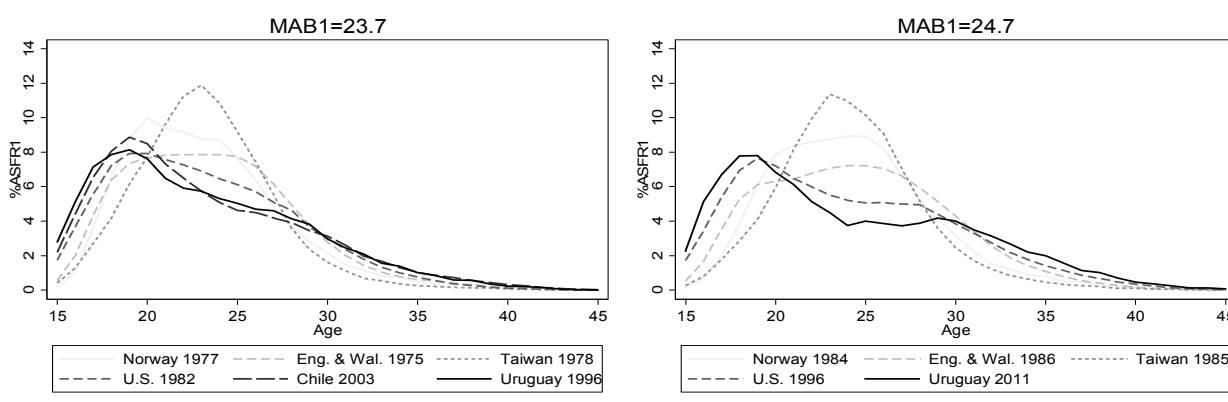

\begin{tabular}{lcr|lrr}
\hline Country and year & sdMAB1 & Mode & Country and year & sdMAB1 & Mode \\
\hline Uruguay 1996 & 5,8 & 19 & Uruguay 2011 & 6,5 & $18-19$ \\
Chile 2003 & 5,7 & 19 & Chile & - & - \\
United States 1982 & 5,0 & $19-20$ & United States 1996 & 5,8 & 19 \\
England \& Wales 1975 & 4,7 & $21-24$ & England \& Wales 1986 & 5,1 & $24-25$ \\
Norway 1977 & 4,3 & 20 & Norway 1984 & 4,4 & $24-25$ \\
Taiwan 1978 & 3,9 & 23 & Taiwan 1985 & 4,0 & 23 \\
\hline
\end{tabular}

Source: own calculations based on data from Human Fertility Database and Human Fertility Collection

\section{Discussion}

Since literature on fertility postponement tends to concentrate solely on the increase in MAB1, studies focusing on dispersion in timing at first birth are scarce. Still, two hypotheses on the evolution of dispersion emerge from the existing literature. On the one hand, while describing the features of the PT model, Kohler et al. (2002) predicted the "rectangularization" of fertility patterns, suggesting that the concentration of age at first birth becomes increasingly narrow once the increase in MAB1 approaches its limits. On the other hand, Sobotka $(2004,2010)$ and Philipov (2017) found evidence to support the hypothesis of rising heterogeneity in first-birth timing throughout the PT.

Aiming to contribute to a broadening of the research agenda in the study of the timing of first births, we examined the evolution of the mean age at first birth and its standard deviation since 1970, as well as changes in age schedule of first birth rates across 21 countries from Europe, East Asia, North and South America. Our results support the hypothesis of a rising heterogeneity in age at first birth throughout the PT (Sobotka 2004; Philipov 2017), and stress the relevance of distinctive regional patterns, which arise in connection to national/regional socio-historical and institutional features. For instance, South American countries, well known for their high levels of social inequality, showed the highest level of dispersion at the onset of 
fertility postponement and an extraordinary increase in the sdMAB1 over a short period.

Additionally, we showed that country-specific distribution of age-specific fertility rates of first birth can reveal four basic patterns of dispersion: three are variants of the usual normally distributed pattern, while the remaining group shows greater heterogeneity, which can be associated with social status polarisation, particularly noticeable in the United States and Latin American countries. Two underlying processes explain the emergence of this pattern: the persistence of high fertility rates at younger ages, often observed in women from lower social strata, and the postponement of first births pioneered by women in middle and upper socioeconomic strata (Lima et al. 2018; Nathan 2015; Pardo/Cabella 2018; Rendall et al. 2010; Sullivan 2005).

Overall, the debate over the proper interpretation of an increasing dispersion is twofold. On the one hand, an increasing dispersion in age at first birth maintaining a unimodal distribution curve tends to be interpreted within the general framework of increasing heterogeneity in the timing of events in the life course, as an indicator of increasing personal autonomy in the pursuit of self-realisation (Billari/Liefbroer 2010; MacMillan 2005). On the other hand, when an increasing variance is associated with a non-normal distribution pattern (usually reaching the highest levels of sdMAB1), it is usually linked to social status polarisation.

In Latin America, where data on fertility by birth order are limited, there is consensus that the shift towards late childbearing will produce a rapid rise in heterogeneity in first-birth schedules, due to the persistence of high teenage fertility rates (CEPAL 2012; Rodriguez/Cavenaghi 2014). It has been shown that Chile and Uruguay, for example, underwent the first stages of fertility postponement with a lower MAB1 and higher standard deviation than those of developed countries. This pattern is also reflected in the emergence of bimodal curves of hazard rates of first birth by age. Even though Burkimsher (2017) interprets non-normal shapes as a transitional stage in the postponement transition, it is likely that Latin American countries are developing a bimodal pattern of their own (Lima et al. 2018; Nathan et al. 2016; Nathan 2015; Pardo/Cabella 2018).

All period trends observed are fostered by a combination of cohort and period factors. Bongaarts/Sobotka (2012) assume that purely period-driven change should leave variance unchanged, while cohort-driven postponement should lead to a decline. Then a stabilised sdMAB1, noticeable in many countries of our sample, suggests the prevalence of period factors of change. But how should the increasing dispersion be interpreted in terms of cohort and period factors? Philipov (2017) assumes that a mixture of both might be behind the increase of sdMAB1, as periodspecific factors persist while changes in ideas influence new cohorts, which "learn" new behaviour as they reach reproductive ages. To make matters more complex, period factors may influence only one stage of the age span. However, when marked socioeconomic disparities are observed, period heterogeneity is expected to be high at the onset of the PT and increase as a result of the widening gaps among younger cohorts entering reproductive ages. 
In light of these results and discussion, three questions may contribute to a more extensive debate and a broader research agenda. First, how should we interpret an increasing sdMAB1? Data on age-specific first birth rates are crucial to understanding reproductive behaviour, but a more rigorous theoretical perspective is indispensable to interpret data within a broader context of social change and to assign meaning to observed trends and patterns.

Second, are we measuring dispersion with the appropriate indicator? At first glance, a straightforward and highly available measure such as the sdMAB1 seems to be the best option in order to capture dispersion of first births. But when the mean changes, it may be appropriate to measure the ratio of the standard deviation to the mean, i.e. the coefficient of variation of age at first birth (CV1) (see Appendix, Fig. A1). ${ }^{5}$ In any case, we favoured the sdMAB1 in this study in order to capture absolute instead of relative variation. Additionally, should we discard the sdMAB1 as dispersion measure when dealing with non-Gaussian shaped curves, considering the underlying assumptions of variance and standard deviation? If so, the interquartile range is a suitable alternative, as it is not based on the assumption of a symmetric distribution. Sobotka (2004) arrived at similar results using the interquartile range, as did we (not shown).

Third, how might dispersion of first births evolve as postponement reaches its "limits"? This is not yet possible to ascertain, but so far, a noticeable decrease in the pace of postponement seems to be coupled to the sdMAB1 plateauing at high levels. Will countries and regions converge around a similar age schedule of first birth rates?

\section{Acknowledgements}

An earlier version of this paper was presented in the Human Fertility Database Symposium (2016) and the Population Association of America 2017 Annual Meeting. We are thankful to two anonymous reviewers and the editors for their comments and suggestions.

5 Data from two countries may help us illustrate this dilemma. In Sweden, the sdMAB1 has increased over the last 25 years, while the CV1 has remained quite stable (17 to 18 percent); however, in the United States, the sdMAB1 has plateaued since 2003, while the CV1 has started to decrease (see Appendix, Fig. A1). Would it be accurate to prefer the CV1 and state that dispersion has remained constant in Sweden and fallen in the United States? 


\section{References}

Balbo, Nicoletta; Billari, Francesco C.; Mills, Melinda 2013: Fertility in advanced societies: A review. In: European Journal of Population 29: 1-38 [doi: 10.1007/s10680-0129277-y].

Basten, Stuart; Sobotka, Tomáš; Zeman, Kryštof 2014: Future fertility in low fertility countries. In: Lutz, Wolfgang; Butz, William P.; Samir K. C. (Eds.): World Population and Human Capital in the 21st Century. Oxford: Oxford University Press.

Beets, Gijs 2010: The Demography of the Age at First Birth: The Close Relationship between Having Children and Postponement. In: Beets, Gijs; Schippers, Joop; Le Velde, Egbert R. (Eds): The Future of Motherhood in Western Societies. New York: Springer: 61-90 [doi: 10.1007/978-90-481-8969-4_6].

Billari, Francesco C. 2004: Becoming an adult in Europe: A macro (/micro)-demographic perspective. In: Demographic Research 3,2: 15-44 [doi: 10.4054/DemRes.2004.S3.2].

Billari, Francesco C.; Liefbroer, Aart C. 2010: Towards a new pattern of transition to adulthood? In: Advances in Life Course Research 15,2-3: 59-75 [doi: 10.1016/j. alcr.2010.10.003].

Billari, Francesco C.; Liefbroer, Aart C.; Philipov, Dimiter 2006: The postponement of childbearing in Europe: driving forces and implications. In: Vienna Yearbook of Population Research 4: 1-17 [doi: 10.1553/populationyearbook2006s1].

Billari, Francesco C.; Wilson, Chris 2001: Convergence towards diversity? Cohort dynamics in the transition to adulthood in contemporary Western Europe. Working Paper 39. Max Planck Institute for Demographic Research: Rostock.

Bongaarts, John; Sobotka, Tomas 2012: A Demographic Explanation for the Recent Rise in European Fertility. In: Population and Development Review 38,1: 83-120 [doi: 10.1111/j.1728-4457.2012.00473.x].

Bongaarts, John; Watkins, Susan Cott 1996: Social interactions and contemporary fertility transitions. In: Population and development review 22,4: 639-682.

Brückner, Hannah; Mayer, Karl Ulrich 2005: De-standardization of the life course: What it might mean? And if it means anything, whether it actually took place? In: Advances in Life Course Research 9: 27-53 [doi: 10.1016/S1040-2608(04)09002-1].

Burkimsher, Marion 2017: Evolution of the shape of the fertility curve: Why might some countries develop a bimodal curve? In: Demographic Research 37,11: 295-324 [doi: 10.4054/DemRes.2017.37.11].

Burkimsher, Marion 2015: Europe-wide fertility trends since the 1990s: Turning the corner from declining first birth rates. In: Demographic Research 32,21: 621-656 [doi: 10.4054/DemRes.2015.32.21].

CEPAL 2012: Panorama Social de América Latina. Santiago de Chile: United Nations Publications.

Chandola, Tarani; Coleman, David A.; Hiorns, R.W. 2002: Distinctive features of agespecific fertility profiles in the English-speaking world: Common patterns in Australia, Canada, New Zealand and the United States, 1970-98. In: Population Studies 56,2: 181-200 [doi: 10.1080/00324720215929].

De Valk, Helga; Liefbroer, Aart 2007: Timing Preferences for Women's Family-Life Transitions: Intergenerational Transmission among Migrants and Dutch. In: Journal of Marriage and Family 69,1: 190-206 [doi: 10.1111/j.1741-3737.2006.00353.x]. 
Duclos, Jean-Yves; Esteban, Joan; Ray, Debraj 2004: Polarization: concepts, measurements, estimation. In: Econometrica 72,6: 1737-1772 [doi: 10.1111/j.14680262.2004.00552.x].

Elzinga, Cees; Liefbroer Aart 2007: De-standardization of family-life trajectories of young adults: A cross-national comparison using sequence analysis. In: European Journal of Population 23,3-4: 225-250 [doi: 10.1007/s10680-007-9133-7].

Esteve, Albert et al. 2012: The "Second Demographic Transition" Features in Latin America: the 2010 Update. Working paper. Centre d'Estudis Demografics, Universitat Autonoma de Barcelona: Barcelona.

Frejka, Tomas; Jones, Gavin W.; Sardon, Jean-Paul 2010: East Asian childbearing patterns and policy developments. In: Population and Development Review 36,3: 579606 [doi: 10.1111/j.1728-4457.2010.00347.x].

Frejka, Tomas; Sardon, Jean-Paul 2006: First birth trends in developed countries: persisting parenthood postponement. In: Demographic Research 15,6: 147-180 [doi: 10.4054/DemRes.2006.15.6].

Furstenberg, Frank F.; Rumbaut, Rubén G.; Settersen Jr, Richard A. (Eds.) 2005: On the frontier of adulthood: Theory, research and public policy. Chicago: University of Chicago Press.

Goldstein, Joshua; Sobotka, Tomas; Jasilioniene, Aiva 2009: The end of "lowest-low" fertility? In: Population and development review 35,4: 663-699.

Gustafsson, Siv; Kalwij, Adriaan 2006: Education and Postponement of Maternity. Economic Analysis for Industrialized Countries. Springer [doi: 10.1007/1-4020-4716-9].

Gustafsson, Siv; Kenjoh, Eiko; Wetzels, Cecile 2002: The role of education on postponement of maternity in Britain, Germany, the Netherlands, Sweden. In: Ruspini, Elisabetta; Dale, Angela (Eds.): The gender dimension of social change: The contribution of dynamic research to the study of women's life courses. Bristol: The Policy Press: 55-79.

Kohler, Hans-Peter; Billari, Francesco C.; Ortega, José Antonio 2002: The emergence of lowest-low fertility in Europe during the 1990s. In: Population Development Review 28,4: 641-680 [doi: 10.1111/j.1728-4457.2002.00641.x].

Lesthaeghe, Ron 2010: The Unfolding Story of the Second Demographic Transition. In: Population and Development Review 36,2: 2011-251 [doi: 10.1111/j.17284457.2010.00328.x].

Liefbroer Aart; Billari, Francesco C. 2010: Bringing norms back in: a theoretical and empirical discussion of their importance for understanding demographic behaviour. In: Population, Space and Place 16,4: 287-305 [doi: 10.1002/psp.552].

Lima, Everton E.C. et al. 2018: The Emergence of Bimodal Fertility Profiles in Latin America. In: Population and Development Review 44,4: 723-743 [doi: 10.1111/padr.12157].

Livi Bacci, Massimo 2008: La sindrome del ritardo e l'autonomia dei giovani. In Un Welfare per crescere. Roma: AREL.

MacMillan, Ross (Ed.) 2005: The Structure of the Life Course: Standardized? Individualized? Differentiated? In: Advances in Life Course Research 9: 1-366.

McLanahan, Sara 2004: Diverging destinies: how children are faring under the Second Demographic Transition. In: Demography 41,4: 607-627 [doi: 10.1353/dem.2004.0033].

Mills, Melinda et al. 2011: Why do people postpone parenthood? Reasons and social policy incentives. In: Human Reproduction Update 17,6: 848-860 [doi: 10.1093/humupd/dmr026]. 
Nathan, Mathías 2017: Polarization of the age at first birth in the Southern Cone. Presented at XXVIII IPC. Cape Town, October 2017.

Nathan, Mathías 2015: La lenta transición hacia un régimen de fecundidad tardía en Uruguay: Ios cambios en la edad al primer hijo entre 1978 y 2011. In: Revista Latinoamericana de Población 17: 37-60.

Nathan, Mathías; Pardo, Ignacio; Cabella, Wanda 2016: Diverging patterns of fertility decline in Uruguay. In: Demographic Research 34,20: 563-586 [doi: 10.4054/DemRes.2016.34.20].

Neels, Karel; Perelli-Harris, Brienna 2013: Heterogeneity in Demographic Change: The Educational Gradient of New Family Behaviors in Europe and the United States. Paper presented at the annual meeting of the Population Association of America, New Orleans.

Ní Bhrolcháin, Marie; Beaujouan, Éva 2012: Fertility postponement is largely due to rising education enrolment. In: Population Studies 66,3: 311-327 [doi: 10.1080/00324728.2012.697569].

Nico, Magda 2014: Variability in the Transitions to Adulthood in Europe: A Critical Approach to De-Standardization of the Life Course. In: Journal of Youth Studies 17,2: 166-82 [doi: 10.1080/13676261.2013.805877].

Nicoletti, Cheti; Tanturri, Maria Letizia 2008: Differences in Delaying Motherhood Across European Countries: Empirical Evidence from the ECHP. In: European Journal of Population 24: 157-183.

Pardo, Ignacio; Cabella, Wanda 2018: A Bimodal Pattern in Age at First Birth in Southern Cone Countries? In: Population Review 57,2: 1-22 [doi: 10.1353/prv.2018.0004].

Philipov, Dimiter 2017: Rising Dispersion in Age at First Birth in Europe: Is it related to Fertility Postponement? VID Working Paper 11. Vienna Institute of Demography: Vienna.

Ravanera, Zenaida; Rajulton, Fernando 2006: Social Status Polarization in the Timing and Trajectories to Motherhood. In: Canadian Studies in Population 33,2: 179-207 [doi: 10.25336/P6Q90M].

Rendall, Michael et al. 2010: Increasingly heterogeneous ages at first birth by education in Southern-European and Anglo-American family-policy regimes: A seven-country comparison. In: Population Studies 64,3: 209-227 [doi: 10.1080/00324728.2010.512392].

Rindfuss, Ronald 1991: The young adult years: Diversity, structural change, and fertility. In: Demography 28,4: 493-512 [doi: 10.2307/2061419].

Rindfuss, Ronald; Brauner-Otto, Sarah 2008: Institutions and the transition to adulthood: Implications for fertility tempo in low-fertility settings. In: Vienna Yearbook of Population Research 2008. Vienna Institute of Demography: Vienna [doi: 10.1553/ populationyearbook2008s57].

Rodriguez, Jorge; Cavenaghi, Suzana 2014: Adolescent and youth fertility and social inequality in Latin America and the Caribbean: what role has education played? In: Genus 70,1: 1-25.

Rosero-Bixby, Luis; Castro-Martín, Teresa; Martín-García, Teresa 2009: Is Latin America starting to retreat from early and universal childbearing? In: Demographic Research 20,9: 169-194 [doi: 10.4054/DemRes.2009.20.9]. 
Schulze, Hans-Joachim; Tyrell, Hartmann 2002: What happened to the European family in the 1980s? The polarization between the family and other forms of private life. In: Kaufmann, Franz-Xaver et al. (Eds.): Family Life and Family Policies in Europe, Volume 2, Problems and Issues in Comparative Perspective. Oxford: Oxford University Press: 69-119.

Sobotka, Tomáš 2017: Post-Transitional Fertility: Childbearing Postponement and the Shift to Low and Unstable Fertility Levels. Working Papers 01. Vienna Institute of Demography: Vienna.

Sobotka, Tomáš 2010: Shifting parenthood to advanced reproductive ages: Trends, causes and consequences. In: Tremmel, Joerg C. (Ed.): A Young Generation Under Pressure? Berlin/Heidelberg: Springer-Verlag: 129-154 [doi: 10.1007/978-3-642-034831_7].

Sobotka, Tomáš 2004: Postponement of childbearing and low fertility in Europe. Amsterdam: Dutch University Press.

Sullivan, Rache/ 2005: The age pattern of first-birth rates among U.S. women: the bimodal 1990s. In: Demography 42,2: 259-273 [doi: 10.1353/dem.2005.0018].

Mathías Nathan ( $₫)$, Ignacio Pardo. Universidad de la República Uruguay, Facultad de Ciencias Sociales (FCS). Montevideo, Uruguay.

E-mail: mathias.nathan@cienciassociales.edu.uy, ignacio.pardo@cienciassociales.edu.uy URL: http://cienciassociales.edu.uy/unidadmultidisciplinaria/nathan-mathias/

URL: http://cienciassociales.edu.uy/unidadmultidisciplinaria/pardo-ignacio/ 


\section{Appendix}

Tab. A1: List of countries by region, data source, and time span

\begin{tabular}{|c|c|c|c|}
\hline Region \& Country & & Source & Time span \\
\hline \multicolumn{4}{|l|}{ Northern Europe } \\
\hline Finland & FIN & HFD & $1982-2012$ \\
\hline Norway & NOR & HFD & $1970-2014$ \\
\hline Sweden & SWE & HFD & $1970-2014$ \\
\hline \multicolumn{4}{|l|}{ Western Europe } \\
\hline Austria & AUT & HFD & 1984-2014 \\
\hline The Netherlands & NLD & HFD & $1970-2012$ \\
\hline England and Wales & GBRTENW & HFC & $1970-2007$ \\
\hline \multicolumn{4}{|l|}{ Southern Europe } \\
\hline Greece & GRC & HFC & 1970-2008 \\
\hline Portugal & PRT & HFD & $1970-2012$ \\
\hline Spain & ESP & HFD & $1975-2014$ \\
\hline \multicolumn{4}{|c|}{ Central \& Eastern Europe } \\
\hline Bulgaria & BGR & HFD & $1970-2009$ \\
\hline Czech Republic & CZE & HFD & $1970-2014$ \\
\hline Hungary & HUN & HFD & $1970-2014$ \\
\hline \multicolumn{4}{|l|}{ Post-Soviet countries } \\
\hline Belarus & BLR & HFD & $1970-2014$ \\
\hline Russia & RUS & HFD & $1970-2014$ \\
\hline Ukraine & UKR & HFD & $1970-2013$ \\
\hline \multicolumn{4}{|l|}{ East Asia } \\
\hline Japan & JPN & HFD & $1970-2012$ \\
\hline Taiwan & TWN & HFD & $1976-2014$ \\
\hline \multicolumn{4}{|l|}{ North America } \\
\hline Canada & CAN & HFD & $1970-2011$ \\
\hline United States & USA & HFD & $1970-2014$ \\
\hline \multicolumn{4}{|l|}{ South America } \\
\hline Chile & $\mathrm{CHL}$ & HFD & $1992-2005$ \\
\hline Uruguay & URY & HFC & 1978-2011 \\
\hline
\end{tabular}


Tab. A2: Percentage of women aged 25-29 who are childless in Latin American countries, 1970-2011

\begin{tabular}{lccccc}
\hline & $1970-77$ & $1978-85$ & $1990-97$ & $1998-2005$ & $2006-2011$ \\
\hline Argentina & & 30.4 & 32.9 & 36.9 & 39.1 \\
Bolivia & 19.1 & & 19.3 & 22.9 & 20.2 \\
Brazil & 29.5 & 28.3 & 29.2 & 30.8 & 39.9 \\
Chile & 15.6 & 26.1 & 27.2 & 31.4 & 39.7 \\
Colombia & 27.1 & 27.2 & 29.1 & 29.4 & \\
Costa Rica & 22.1 & 22.2 & & 25.9 & 36.1 \\
Ecuador & 18.8 & 20.6 & 23.9 & 23.4 & 24.8 \\
El Salvador & & & 25.6 & & 26.4 \\
Mexico & 23.2 & & 24.1 & 27.6 & 30.2 \\
Nicaragua & 15.5 & & 14.7 & 17.5 & \\
Panama & 17.7 & 21.0 & 24.5 & 26.1 & 28.3 \\
Peru & & & 26.3 & & 33.3 \\
Puerto Rico & 23.5 & 25.2 & 33.0 & & \\
Uruguay & 32.8 & 32.1 & 34.4 & & 43.7 \\
Venezuela & 26.9 & & 27.2 & 28.2 & 33.4 \\
\hline
\end{tabular}

Source: Esteve et al. (2012), using IPUMS data files, and authors' computations for Argentina, Bolivia, Chile and Venezuela 2006-2011, using census tabulations from national statistical offices (Argentina 2010; Bolivia 2012; Venezuela 2011) and microdata from the Chilean survey Encuesta de Caracterización Socioeconómica Nacional (CASEN 2011). 
Fig. A1: Evolution of the mean age at first birth and its coefficient of variation by region and country
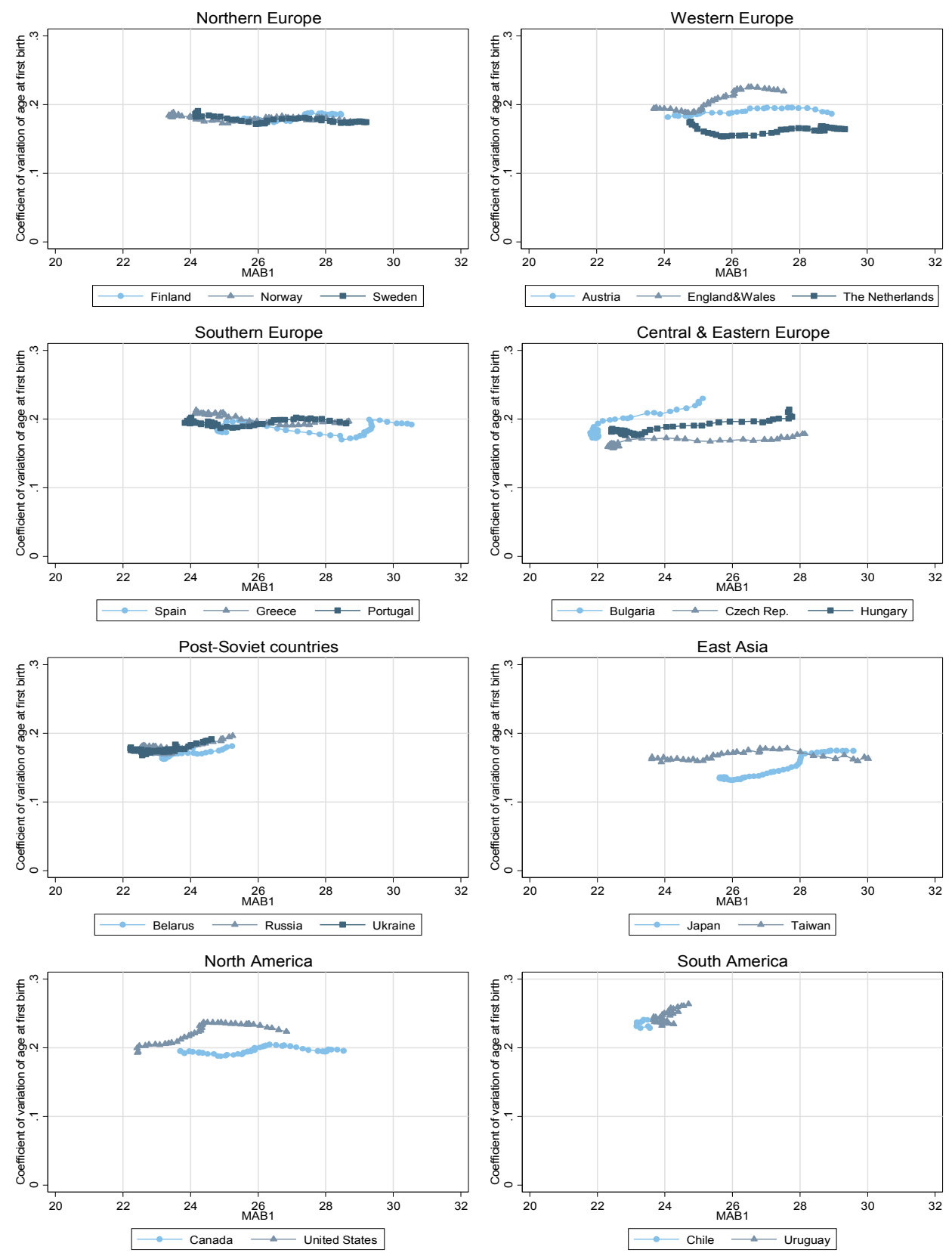

Source: own calculations based on data from Human Fertility Database and Human Fertility Collection 


\section{Comparative Population Studies}

WWW.comparativepopulationstudies.de

ISSN: 1869-8980 (Print) - 1869-8999 (Internet)

\section{Published by}

Prof. Dr. Norbert F. Schneider

Federal Institute for Population Research D-65180 Wiesbaden / Germany

\section{(c) BY-SA}

2019

\section{Managing Editor \\ Prof. Philip Rees \\ Dr. Katrin Schiefer}

\section{Copy Editor}

Julia Luther

\section{Editorial Assistant}

Beatriz Feiler-Fuchs

Wiebke Hamann

\section{Layout \\ Beatriz Feiler-Fuchs \\ E-mail:cpos@bib.bund.de}

\section{Scientific Advisory Board}

Karsten Hank (Cologne)

Michaela Kreyenfeld (Berlin)

Marc Luy (Vienna)

Natalie Nitsche (Vienna)

Peter Preisendörfer (Mainz)

Zsolt Spéder (Budapest)

Rainer Wehrhahn (Kiel)

\section{Board of Reviewers}

Martin Abraham (Erlangen)

Laura Bernardi (Lausanne)

Hansjörg Bucher (Bonn)

Claudia Diehl (Konstanz)

Andreas Diekmann (Zurich)

Gabriele Doblhammer-Reiter (Rostock)

Jürgen Dorbritz (Wiesbaden)

Anette Eva Fasang (Berlin)

E.-Jürgen Flöthmann (Bielefeld)

Alexia Fürnkranz-Prskawetz (Vienna)

Beat Fux (Salzburg)

Joshua Goldstein (Berkeley)

Sonja Haug (Regensburg)

Hill Kulu (Liverpool)

Aart C. Liefbroer (The Hague)

Kurt Lüscher (Konstanz)

Emma Lundholm (Umeå)

Nadja Milewski (Rostock)

Dimiter Philipov (Vienna)

Roland Rau (Rostock)

Tomáš Sobotka (Vienna)

Jeroen Spijker (Barcelona)

Olivier Thévenon (Paris)

Helga de Valk (Brussels)

Heike Trappe (Rostock)

Michael Wagner (Cologne) 